\title{
Aerodynamic Characteristics and Glide-Back Performance of Langley Glide-Back Booster
}

\author{
Bandu N. Pamadi ${ }^{1}$ Peter F. Covell ${ }^{2}$, Paul V. Tartabini ${ }^{3}$ and Kelly J. Murphy ${ }^{4}$ \\ NASA Langley Research Center, Hampton, VA
}

\begin{abstract}
NASA-Langley Research Center is conducting system level studies on an-house concept of a small launch vehicle to address NASA's needs for rapid deployment of small payloads to Low Earth Orbit. The vehicle concept is a three-stage system with a reusable first stage and expendable upper stages. The reusable first stage booster, which glides back to launch site after staging around Mach 3 is named the Langley Glide-Back Booster (LGBB). This paper discusses the aerodynamic characteristics of the LGBB from subsonic to supersonic speeds, development of the aerodynamic database and application of this database to evaluate the glide back performance of the LGBB. The aerodynamic database was assembled using a combination of wind tunnel test data and engineering level analysis. The glide back performance of the LGBB was evaluated using a trajectory optimization code and subject to constraints on angle of attack, dynamic pressure and normal acceleration.
\end{abstract}

\section{Nomenclature}

$\begin{array}{ll}A_{N} & \text { normal acceleration, g's } \\ b_{r e f} & \text { wing span } \\ \alpha & \text { angle of attack, deg } \\ \beta & \text { sideslip, deg } \\ C_{D} & \text { drag coefficient } \\ \Delta C_{D} & \text { incremental drag coefficient } \\ C_{L} & \text { lift coefficient } \\ \Delta C_{L} & \text { incremental lift coefficient } \\ C_{l} & \text { rolling moment coefficient } \\ C_{m} & \text { pitching moment coefficient } \\ C_{n} & \text { yawing moment coefficient } \\ C_{Y} & \text { side force coefficient } \\ \delta_{c} & \text { canard deflection, deg } \\ \delta_{e} & \text { elevon deflection, deg } \\ \gamma & \text { flight path angle, deg } \\ \mathrm{h} & \text { altitude, ft } \\ L_{r e f} & \text { vehicle reference length, ft } \\ \mathrm{M} & \text { Mach number }\end{array}$

\footnotetext{
${ }^{1}$ Senior Aerospace Engineer, Associate Fellow AIAA.

${ }^{2}$ Senior Aerospace Engineer, Senior Member AIAA.

* Aerospace Engineer, Member AIAA.

4 Aerospace Engineer, Member AIAA
} 
$\sigma \quad$ bank angle, deg

velocity, $\mathrm{ft} / \mathrm{s}$

\section{Introduction}

A need exists for new small launch vehicles (SLVs) for the deployment of military, civil and commercial satellites either singly or in satellite constellations and architectures. The SLVs must be highly responsive in providing rapid deployment of small payloads at significantly lower launch costs, improved reliability and maintainability. To address these issues, the Vehicle Analysis Branch of NASA's Langley Research Center is conducting system level studies on an in-house concept of a small launch vehicle. This vehicle concept is a three-stage system with a reusable first-stage booster and expendable upper stages. The design is based on the use of low cost pressure-fed LOX/RP engines developed by Microcosm ${ }^{1}$ and the slide-in propulsion module concept of Starcraft Boosters Inc. ${ }^{2}$ An advantage of this concept is that the entire propulsion system can be removed and serviced off-line and kept ready for a new launch to reduce the turnaround time. This SLV system is designed to place about $330 \mathrm{lbs}$ in a polar orbit at $150 \mathrm{~nm}$.

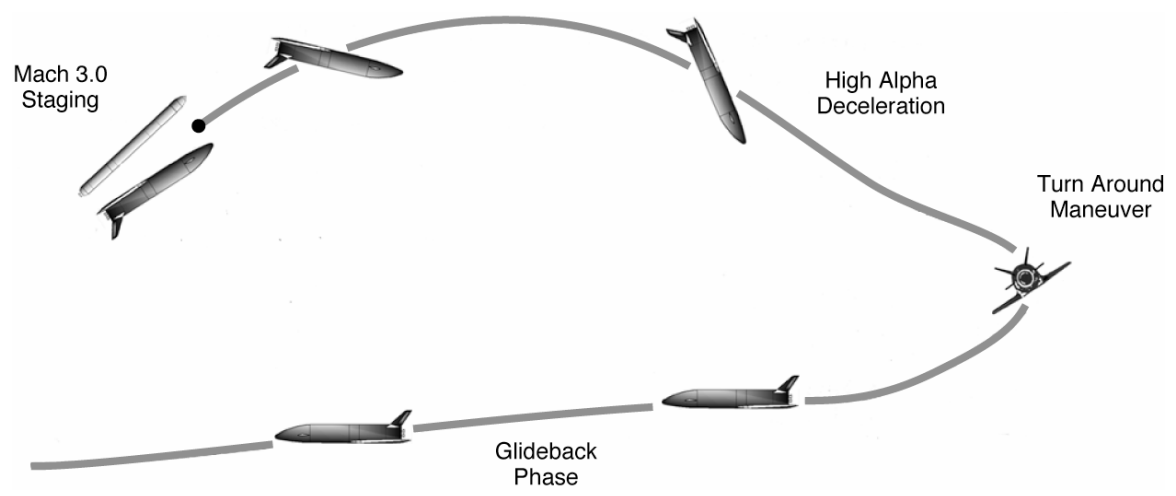

Figure 1. Illustration of the flight profile.

A schematic diagram of the flight profile is presented in Fig. 1. The LGBB is designed to stage at approximately Mach 3, fly un-powered at high angles of attack (to increase drag to keep the down range to a minimum), turn around and return to the launch site. If staging were to occur at a higher Mach number, the booster may experience aerodynamic heating and require a dedicated thermal protection system. The glideback booster is named the Langley Glide Back Booster (LGBB). After staging, the expendable upper stages continue further and a second staging occurs around Mach 15. The unpowered glideback of the reusable booster eliminates the need for an air-breathing propulsion subsystem and avoids associated maintenance and checkouts needed prior to each launch.

The objective of this paper is to present aerodynamic characteristics from subsonic to supersonic speeds, discuss the development of the aerodynamic database and application of this database

to evaluate the glide back performance of the LGBB on its return to launch site. The aerodynamic database was assembled using a combination of subsonic, transonic and supersonic wind tunnel test data and engineering level analysis using APAS (Aerodynamic Preliminary Analysis System). The ascent and glideback trajectories were generated using the three degree-of-freedom (3-DOF) POST (Program to Optimize Simulated Trajectories). The lateral/directional aerodynamic characteristics of the LGBB are discussed in this paper but the lateral/directional motion was not addressed in POST simulations of the glideback trajectory. The altitude margin, which is defined as the height of the booster when it returns to the launch site was used as a metric for evaluating the glideback performance subject to limits on angle of attack, dynamic pressure and normal acceleration. 


\section{VEHICLE DESCRIPTION}

The first stage vehicle is a pressure-fed LOX/kerosene, reusable, wing-body booster similar to the Starcraft booster design. ${ }^{2}$ A schematic diagram of the small launch vehicle is shown in Fig. 2 and a three-

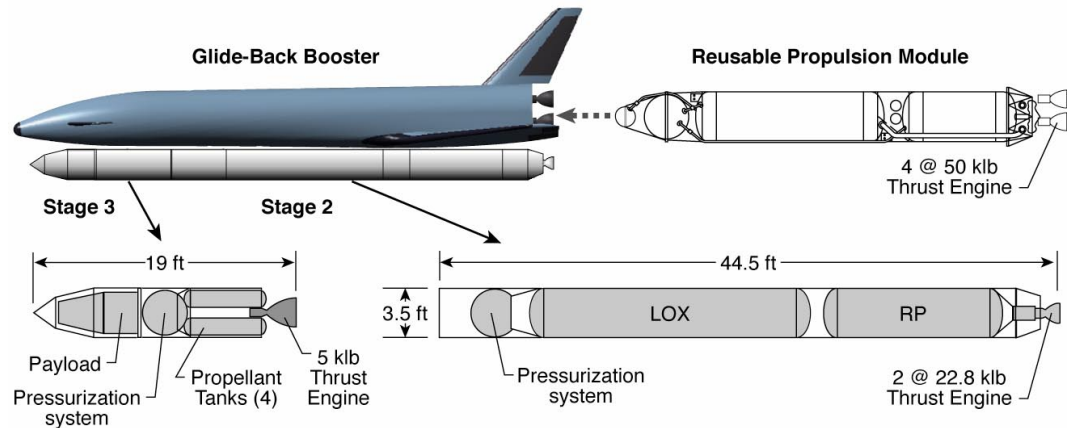

Figure 2. Schematic diagram of the small launch vehicle.

view drawing of the LGBB is presented in Fig. 3. The main wing of the LGBB has a leading edge sweep of $45 \mathrm{deg}$, a dihedral of $6 \mathrm{deg}$ and an 81-deg leading edge strake similar to the wing of the Space Shuttle Orbiter ${ }^{3}$ and the X-34 Technology Demonstrator Vehicle ${ }^{4}$. The wing is sized to provide a landing speed of around $150 \mathrm{kt}$. The vehicle also features forward located canards, full-span split elevons on the main wing, a conventional centerline vertical tail and rudder/speed-brake. The booster propulsion system consists of four 50-Klb thrust (vacuum), pressure-fed engines based on Microcosm designs. ${ }^{1}$ These engines have two-axis gimbal capability for vehicle control during the boost phase. The second stage design mirrors

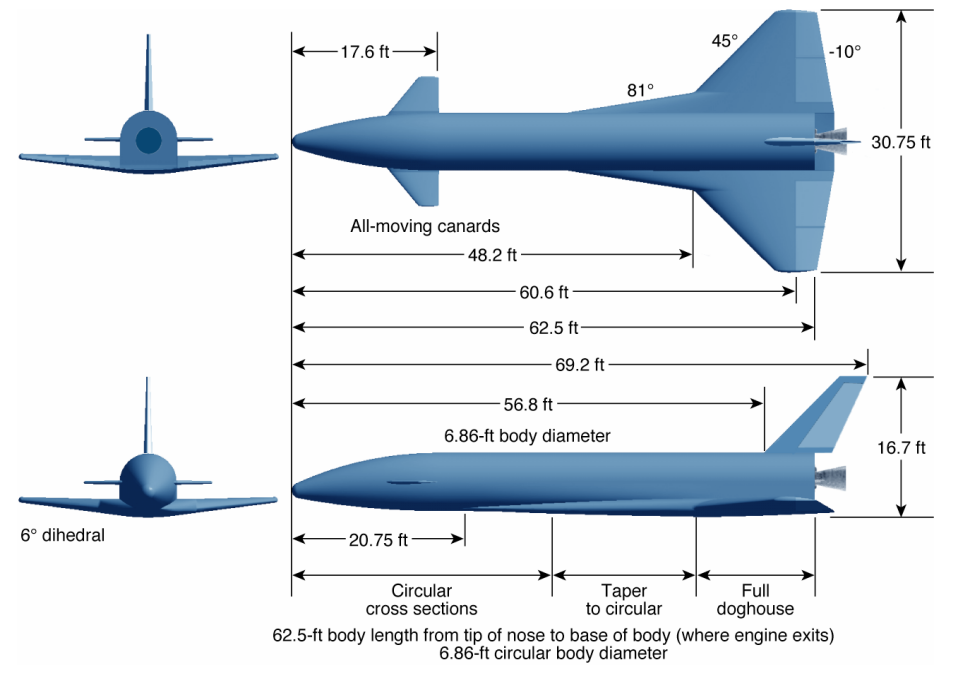

Figure 3. Three-view diagram of the glideback booster. the design of the Microcosm Sprite core stage and uses two pressure-fed 22.8-Klb thrust engines. The third stage design also mirrors the Microcosm Sprite third-stage design and the engine used in this study is based on the qualified Microcosm pressure-fed 5.5-Klb-thrust motor.

The characteristics of the small launch vehicle are presented in Table 1. At staging, the booster (LGBB) has a weight of 28,915 lbf (dry weight) and its center of gravity was estimated to be located at $35.0883 \mathrm{ft}(56.14 \%)$ from the nose. 
Table 1. Characteristics of Small Launch Vehicle

\begin{tabular}{lccc}
\hline \hline \multicolumn{1}{c}{ Characteristic } & Booster & $\begin{array}{c}\text { Second } \\
\text { Stage }\end{array}$ & $\begin{array}{c}\text { Third } \\
\text { Stage }\end{array}$ \\
\hline Gross Weight, lbf & 88,727 & 23,859 & 4,080 \\
$\begin{array}{l}\text { Dry Weight, lbf } \\
\text { Number of Engines }\end{array}$ & 28,915 & 3,166 & 1,104 \\
$\begin{array}{l}\text { Thrust per engine } \\
\text { (vacuum), lbf }\end{array}$ & 50,000 & 22,402 & 5,490 \\
$\begin{array}{l}\text { ISP per engine } \\
\text { (vacuum), sec }\end{array}$ & 275.0 & 303.1 & 298.2 \\
$\mathrm{Engine}^{2}$ Exit area, & 3.34 & 6.79 & 1.70
\end{tabular}

\section{WIND TUNNEL TEST FACILITIES}

Brief descriptions of various Langley Research Center (LaRC) wind tunnel facilities used in generating the test data are presented below. Detailed information on these LaRC test facilities may be found in Ref. 5 and 6. Also, some tests on the LGBB model were conducted ${ }^{7}$ in the Aerodynamic Research Facility at NASA's Marshall Space Flight Center (MSFC).

LaRC 16-Foot Transonic Tunnel: The Langley16-Foot Transonic Tunnel is a closed circuit, singlereturn, continuous flow atmospheric tunnel with a slotted wall, octagonal test section. The test gas is air with an air exchange for cooling. The nominal Mach number range for the facility is 0.2 to 1.3 . Speeds up to Mach 1.05 are obtained with the main drive fans and speeds above Mach 1.05 are obtained with combination of the main drive fans and test-section plenum suction via a nine-stage axial compressor. The slotted octagonal test section nominally measures 15.5 feet across the flats. The useable test section length is 22 feet for speeds up to Mach 1.0 and 8 feet for speeds above Mach 1.0. The tunnel main support strut has a nominal angular travel of -10 to +25 degrees. The strut head has remote rotary control so that the model and sting can be rolled as a unit from -90 to +90 degrees. Lateral-aerodynamic force testing can be done by rolling the model through \pm 90 degree range and traversing the main tunnel support system in the vertical plane. Generally, the model size for subsonic testing is dictated from blockage considerations and reflected shock disturbances for supersonic speeds. Blockage and shock reflection criteria for this facility can be found in Ref. 5. As a general rule, testing is not permitted between Mach numbers of 0.98 to 1.05 because of both subsonic and supersonic wall interference effects. The unit Reynolds number varies from 2.0 to $4.0 \times 10^{6}$ per ft.

LaRC Unitary Plan Wind Tunnel: The LaRC UPWT is a closed-circuit, continuous-running, pressure tunnel with two test sections that are nominally $4 \mathrm{ft}$ by $4 \mathrm{ft}$ in cross section and seven $\mathrm{ft}$ long. The Mach number range is 1.5 to 2.86 in Test Section I and 2.3 to 4.63 in Test Section II. The stagnation pressure can be varied up to a maximum of approximately 50 psia in Test Section I and approximately 100 psia in Test Section II. The nozzle-throat-to-test-section area ratio is varied by adjusting a lower asymmetric sliding block that provides continuous variation of the Mach number. Tunnel stagnation temperatures are typically $125^{\circ} \mathrm{F}$ for Test Section I and $150^{\circ} \mathrm{F}$ for Test Section II. Test Reynolds numbers usually range from 1.0 to $5.0 \times 10^{6}$ per $\mathrm{ft}$ with a capability to reach up to 6.0 million per foot for certain conditions. The basic model support mechanism is a horizontal wall-mounted strut that is capable of forward and aft travel of over $3 \mathrm{ft}$ 


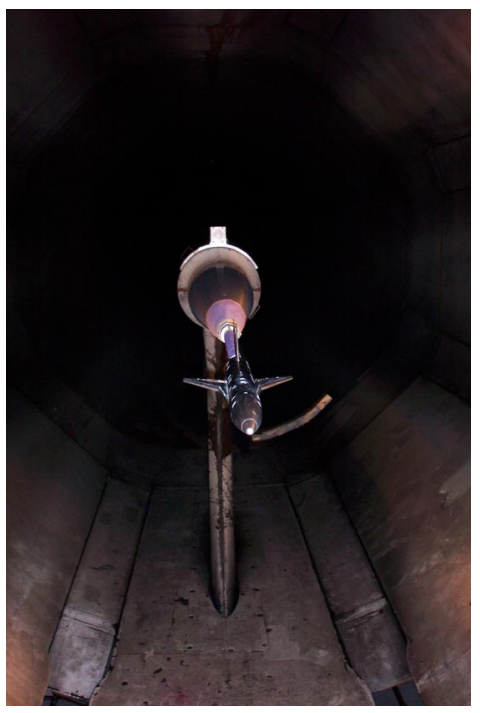

Figure 4 (a).LGBB Model in Langley16-Foot Transonic Tunnel.

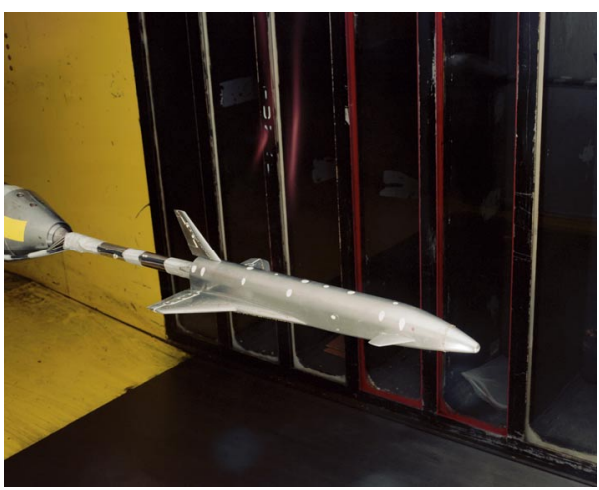

Figure 4(b). LGBB Model in UPWT.

iin the streamwise direction. A main sting support attached to the strut can transverse laterally \pm 20 in and can provide a yaw capability of $\pm 12^{\circ}$. Forward of the main sting support is the angle-of-attack mechanism which provides pitch motion from $-15^{\circ}$ to $+30^{\circ}$. A roll mechanism can be installed ahead of the pitch mechanism to provide continuous roll motion over a $310^{\circ}$ range.

Photographs of the model mounted in the 16-Foot Transonic Tunnel and the UPWT are presented in Fig. 4(a) and 4(b).

\section{Models, Instrumentation and Test Procedure}

The reference dimensions of the wind tunnel models in relation to full scale vehicle are presented in Table 2. As said before, some tests were also done on a $1.028 \%$ scale model of the LGBB at subsonic and supersonic speeds in the Aerodynamic Research Facility at MSFC ${ }^{7}$. For these tests, the angle of attack ranged from -8 to $+8 \mathrm{deg}$, sideslip was zero and control surface deflections were not considered.

Table 2. Reference Dimensions for LGBB

\begin{tabular}{|l|c|c|c|}
\hline $\begin{array}{l}\text { Reference } \\
\text { Dimension }\end{array}$ & $\begin{array}{c}\text { Full-Scale } \\
\text { Flight Vehicle }\end{array}$ & $\begin{array}{c}\text { Model } \\
\text { 16-Foot Transonic Tunnel }\end{array}$ & $\begin{array}{c}\text { Model } \\
\text { UPWT }\end{array}$ \\
\hline Scale & 1.0 & $2.73 \%$ & $1.75 \%$ \\
\hline Sref & $62640 \mathrm{in}^{2}$ & $46.69 \mathrm{in}^{2}$ & $19.18 \mathrm{in}^{2}$ \\
\hline Lref & $750 \mathrm{in}$ & $20.48 \mathrm{in}$ & $13.13 \mathrm{in}$ \\
\hline Bref & $369 \mathrm{in}$ & $10.07 \mathrm{in}$ & $6.46 \mathrm{in}$ \\
\hline $\begin{array}{l}\text { Moment Reference } \\
\text { Point (68\% Lref) }\end{array}$ & $510 \mathrm{in}$ & $13.92 \mathrm{in}$ & $8.93 \mathrm{in}$ \\
\hline
\end{tabular}


To ensure a turbulent boundary layer over the model, a 0.1 " wide transition strip consisting of No. 120 grit was placed on the model for the 16-foot tunnel tests and a band of single spaced No. 35 sand grit was placed on the model for the Unitary tunnel tests. These transition strips were placed approximately 1 inch aft of the nose and 0.4-inches aft streamwise from the leading edge of the wing, canard and vertical tail surfaces. The grit size and location were determined by following the guidelines described in Ref. 8-10. Base and cavity pressures were measured on all models in 16-Foot Transonic Tunnel and UPWT tests but corrections were not applied to measured aerodynamic coefficients.

For tests in the 16-Foot Transonic Tunnel, the angle of attack varied from -4 deg to +14 deg except for Mach 0.3 where it ranged from -4 to $+24 \mathrm{deg}$. For UPWT, the angle of attack ranged from -4 to +48 deg. The sideslip was in the range of -6 deg to +6 deg for tests in both 16-Foot Transonic Tunnel and the UPWT. The lateral/directional test data were obtained for sideslip held fixed at -4 and +4 (16-Foot tests) and -2 and +2 (UPWT) deg with angle of attack variations. Also, some limited sideslip sweeps from -6 to $+6 \mathrm{deg}$ with angle of attack held fixed at 0 and $12 \mathrm{deg}$ (16-Foot Transonic Tunnel) and alpha held fixed at $0,6,12,18,24$ and $30 \mathrm{deg}$ (UPWT). The elevon deflections ranged from -30 to $+15 \mathrm{deg}$ for $16-$ Foot Transonic Tunnel tests and from -30 deg to +20 deg for UPWT tests. The aileron deflections (one sided, left elevon deflected, right elevon zero) for both tests ranged from -30 to $+20 \mathrm{deg}$. The rudder deflections ranged from 0 to $+15 \mathrm{deg}$ for 16-Foot Transonic tunnel tests and 0 to $-30 \mathrm{deg}$ for the UPWT tests, The test parameters are summarized in Table 4.

\section{Table 3. Summary of LGBB Langley Test Conditions}

\begin{tabular}{|l|c|c|c|c|c|c|c|}
\hline Facility & $\begin{array}{c}\text { Mach } \\
\text { Number }\end{array}$ & $\begin{array}{c}\text { Reynolds } \\
\text { Number } \\
\text { Million per ft }\end{array}$ & $\begin{array}{c}\text { Alpha } \\
\text { deg }\end{array}$ & $\begin{array}{c}\text { Sideslip } \\
\text { deg }\end{array}$ & $\begin{array}{c}\text { Elevons } \\
\text { deg }\end{array}$ & $\begin{array}{c}\text { Canard } \\
\text { deg }\end{array}$ & $\begin{array}{c}\text { Rudder } \\
\text { deg }\end{array}$ \\
\hline $\begin{array}{l}\text { 16-Foot } \\
\text { Transonic } \\
\text { Tunnel }\end{array}$ & $\begin{array}{c}0.3 \text { to } \\
1.3\end{array}$ & 1.0 to 4.0 & -4 to 14 & -6 to 6 & -30 to +15 & -10 to +10 & 0 to +15 \\
\hline UPWT & $\begin{array}{c}1.6 \text { to } \\
4.6\end{array}$ & 1.0 to 4.0 & -5 to 48.0 & -6 to 6 & -30 to +20 & -30 to +20 & 0 to -30 \\
\hline
\end{tabular}

The aerodynamic forces and moments were measured using six component strain gage balances. The force and moment data were acquired in a "pitch and pause" manner. Example schlieren photographs of LGBB model in UPWT at Mach 3, alpha=20 deg and 40 deg are presented in Fig. 5. 


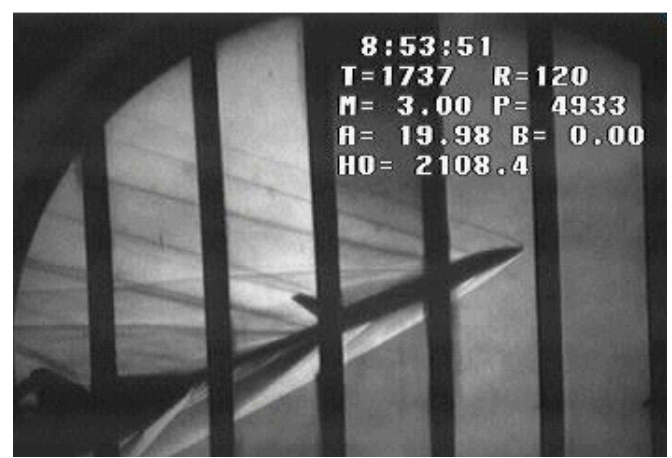

$\operatorname{Mach}=$ 3, Alpha = 20.0 deg.

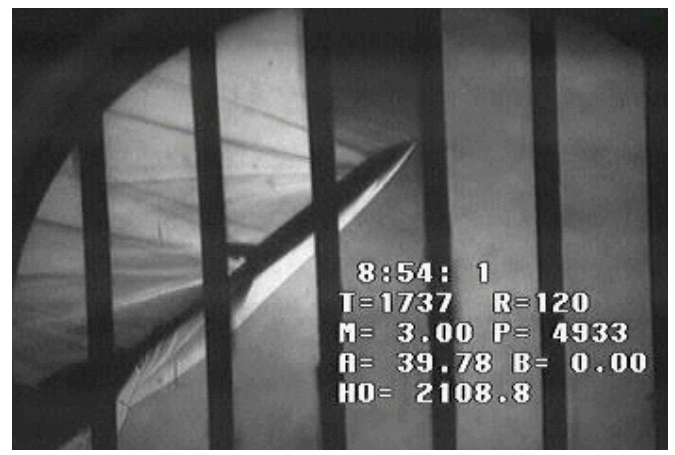

$\operatorname{Mach}=3$, Alpha $=40.0$ deg.

Fig. 5. Schlieren photographs of LGBB in UPWT at Mach 3.

\section{Development of Aerodynamic Database}

The LGBB aerodynamic database discussed here is limited to longitudinal aerodynamic coefficients because only 3-DOF POST simulations were performed in this study. The current version of the 3-DOF LGBB aerodynamic data consists of the static longitudinal aerodynamic coefficients (lift, drag and pitching moment coeffcients) for the baseline vehicle (zero control surface deflections) and incremental coefficients (with respect to the baseline vehicle) for the canards and elevon deflections. The Mach number ranges from 0.3 to 4.5 with closely spaced values in the transonic regime. The angle of attack varies from -4 deg to 20 deg for $\mathrm{M}=0.3$ to 1.2 and from $-5 \mathrm{deg}$ to $48 \mathrm{deg}$ for $\mathrm{M}=1.6$ to 4.5 . The elevon deflections (positive trailing edge down) range from $-30 \mathrm{deg}$ to $+15 \mathrm{deg}$ for Mach 0.3 to 1.2 and from -30 deg to +20 deg for Mach 1.6 to 4.5. The aileron deflections (left elevon deflected, right elevon held at zero) from -30 deg to $+30 \mathrm{deg}$ for Mach 0.3 to 1.2 and from -30 to +20 deg for Mach 1.6 to 4.5. The speedbrake deflections were not considered in this study. The current version of the aerodynamic database does not include control surface hinge moments, landing gear deployment, ground effects and the dynamic or damping derivatives.
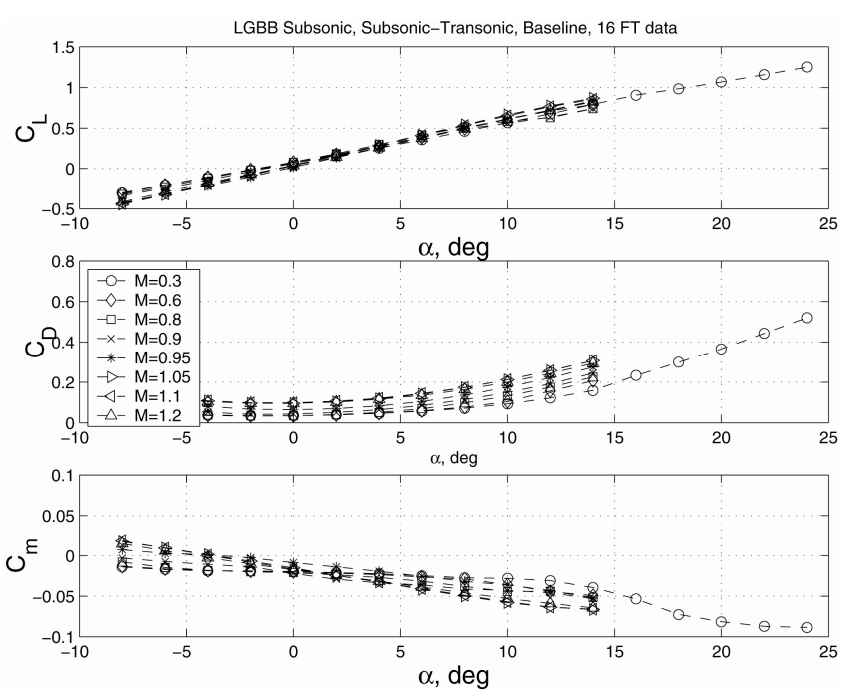

Figure 6. Longitudinal aerodynamic characteristics at subsonic and transonic speeds.
The data in the aero database is mainly based on the test data generated from tests in the 16-Foot Transonic Tunnel and the UPWT. However, several gaps exist in the 16-Foot Transonic Tunnel test data, such as the angle of attack going only up to +14 deg for Mach 0.6 to 1.2 with an exception for Mach 0.3 tests where the data was obtained up to an angle of attack of $24 \mathrm{deg}$. To fill these gaps and populate the database at subsonic/transonic Mach numbers up to an angle of attack of $20 \mathrm{deg}$, the APAS (Aerodynamic Preliminary Analysis System) was used. The APAS is an interactive computer code capable of providing quick engineering lelvel estimates of aerodynamic coefficients from 
subsonic to hypersonic speeds ${ }^{11,12}$. The subsonic/low supersonic module is called the UDP (Unified distribution Panel) and the high supersonic/hypersonic module is called the HABP (Hypersonic Arbitrary Body Program). At subsonic and low supersonic speeds, the UDP module utilizes a combination of slender body theory, source and vortex panel distributions, and empirical methods for viscous and wave drag estimations. The HABP module uses the same geometry model as that used in UDP. The HABP module has various analysis options like tangent cone, tangent wedge, Newtonian impact methods etc. The approach taken was to run APAS for the known test conditions of the 16-Foot Transonic tests, and then anchor the APAS predictions so that a close match with the 16-Foot Transonic Tunnel data is obtained. Then, use this "anchored APAS" predictions to populate the database where 16-Foot Transonic test data is not available. Since the UDP uses linear methods, the angle of attack range in APAS calculations for Mach 0.3 to 1.2 is restricted to 20 deg above which the nonlinearities in the variation of aerodynamic coefficients, particularly in the pitching moment coefficient become significant as observed in the Mach 0.3 test data and discussed later.

\section{Trajectory Simulation}

The ascent and glideback trajectory analysis was performed using the POST ${ }^{13}$ (Program to Optimize Simulated Trajectories), a generalized trajectory simulation and optimization code that has been widely used to design and analyze trajectories for a range of aerospace vehicles. POST was used to model and optimize the three-degree-of-freedom powered ascent trajectory and the unpowered booster glideback to the launch site. An oblate Earth gravity model was assumed and atmospheric properties and winds were modeled using the 1999 GRAM $^{14}$ (Global Reference Atmosphere Model).
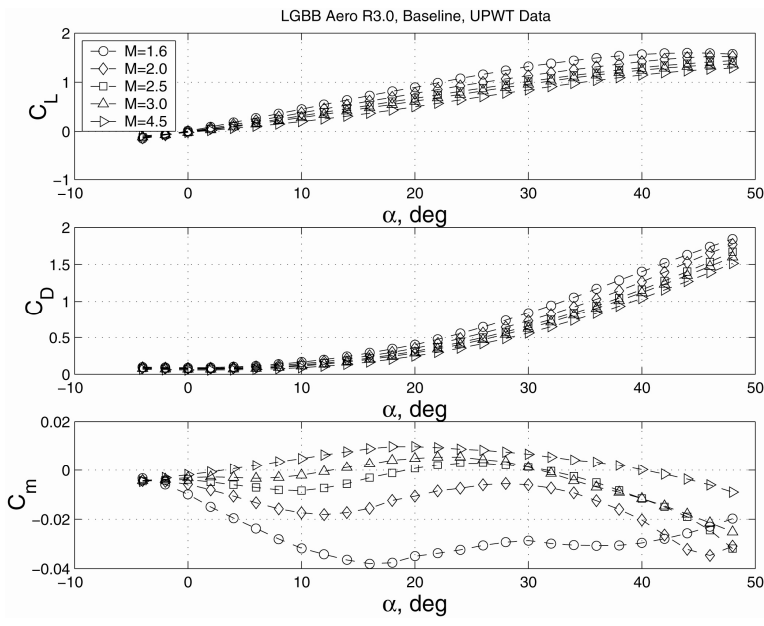

Figure 7. Longitudinal aerodynamic characteristics at supersonic speeds.
The reference mission for the small launch vehicle considered in this study was to deliver a payload of $330 \mathrm{lbs}$ to a $150 \mathrm{~nm}$ circular polar orbit. The launch site was assumed to be Vandenberg Air Force Base and the vehicle was launched towards the south to avoid flying over land. The ascent trajectory was optimized by adjusting the pitch-angle profile to maximize the weight inserted into the target orbit. Additional details on the ascent trajectory simulation are available in Ref. 15.

The glideback trajectory was optimized by adjusting the booster's angleof-attack, bank angle, canard and elevon deflection profiles to maximize the return altitude over the launch site. Maximizing the return altitude provides altitude margin that may be needed to account for offnominal conditions, dispersions in atmos-

pheric conditions, winds and terminal area energy management (TAEM) constraints. These issues were not addressed in this study. Further analysis considering these factors is required to ensure that the altitude margin attained in this study is adequate.

For the glideback trajectory, the peak dynamic pressure was bounded at $300 \mathrm{psf}$ and the normal acceleration was limited to $2.3 \mathrm{~g}$ 's. In the initial part of the glideback trajectory, the elevons were used as "drag" devices to aid in arresting the booster's down range and the canards were used to balance the pitching moment. At supersonic speeds (above Mach 1.6), the angle-of-attack was permitted to assume any value between -4 and $48 \mathrm{deg}$. However, to remain within the limits of the aerodynamic database, the angle of attack below Mach 1.2 was limited to $20 \mathrm{deg}$. For Mach numbers from 1.2 to 1.6, the max alpha limit transitioned smoothly from $20 \mathrm{deg}$ to $48 \mathrm{deg}$. A feedback control scheme was used to modulate the bank 
angle, which was adjusted according to the heading error (i.e., difference between the vehicle heading and the heading to the launch site). Thus, POST controlled the bank vs. heading error profile. Since the winds had a significant effect on the glideback trajectory, a worst-case month (July) was used to determine the effect of winds on altitude margin.

\section{Results and Discussion}

\section{Aerodynamic characteristics:}

The variation of lift, drag and pitching moment coefficient with angle of attack at various Mach numbers are presented in Figs. 6 and 7. As observed in Fig. 6, the model does not encounter stall up to $24^{\circ}$ angle of attack at Mach 0.3. For the given moment reference point of $68 \%$ body length, the model is statically stable in pitch for the angle of attack range tested at subsonic and transonic speeds. The LGBB full scale vehicle (after staging) with its estimated center of gravity at $56.14 \%$ body length will be even more stable in pitch. At low supersonic speeds, for example at Mach 1.6, the model is statically stable in pitch up to about 12 deg angle of attack but becomes unstable for higher angles of attack. The angle of attack at which the model becomes unstable decreases with Mach number and above Mach 3, it is unstable for all angles of attack from 0 to $48 \mathrm{deg}$. However, the model exhibits a stable break in the angle of attack range of 20 to $30 \mathrm{deg}$. This type of variation in pitching moment coefficient is typical of wing-body configurations at hypersonic speeds.
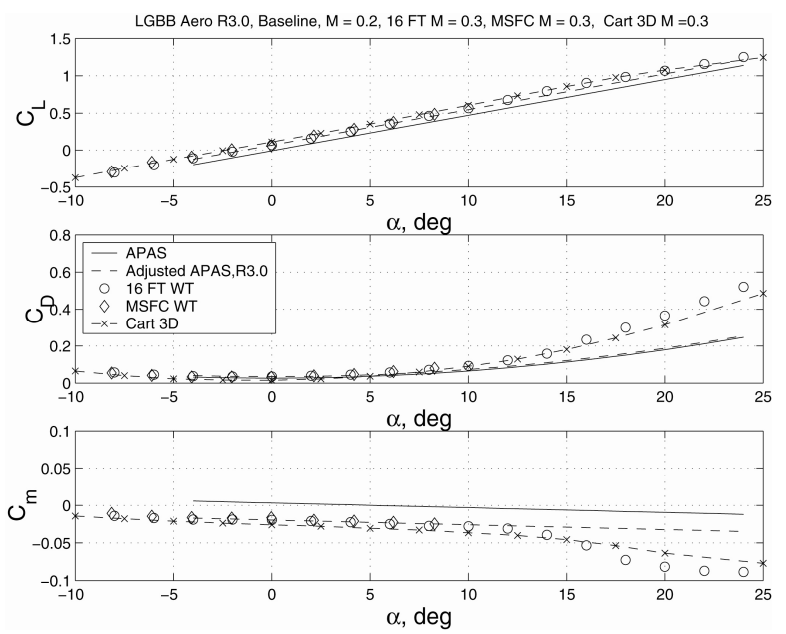

Figure 8. Comparison of longitudinal characteristics at Mach $=\mathbf{0 . 3}$.
A comparison of measured lift, drag and pitching moment coefficients for the baseline configuration at subsonic, transonic and supersonic speeds with available CART3D and OVERFLOW computations are shown in Figs 8 to 10 . The Cart $3 \mathrm{D}^{\mathbf{1 6}}$ is an unstructured, Euler CFD package which includes utilities to import geometry import from most commercially available CAD package, and to perform surface modeling and mesh generation. The flow solver is called Flowcart. The OVERFLOW $^{17}$ code is a structured, compressible Navier-Stokes flow solver that uses a formulation of finite differences in space with implicit time stepping. It is observed that CART3D computations are in good agreement with wind tunnel test data except that the

pitching moment coefficient deviates slightly from wind tunnel data above 15 deg alpha both at Mach 0.3 and 4.5. The OVERFLOW computations are in excellent agreement with wind tunnel test data at Mach 1.2. The APAS estimates, particularly the pitiching moment coefficient, at Mach 0.3 and 1.2 differ from the wind tunnel test data but the adjusted APAS (zero shift to match the 16-Foot Transonic Tunnel data at alpha $=0$ ) gives a much better agreement with the test data. It may be noted that the pitching moment coefficient variation becomes appreciably nonlinear for $\alpha>20 \mathrm{deg}$. In view of this, the APAS predictions used to fill the gaps in the aero database were limited to $\alpha \leq 20$ for Mach below 1.2. Even though APAS is not used in the aero database for Mach >1.6, it is interesting to note that APAS predictions of lift and drag coefficients are in fair agreement with the UPWT test data but the pitching moment coefficient differs considerably for $\alpha>20 \mathrm{deg}$.

The variation of the untrimmed lift-to-drag ratio with angle of attack for various Mach numbers is presented in Fig. 11. At low subsonic speeds, the vehicle has a lift-to-drag ratio as high as 6 at low angles of attack. However, as Mach number increases the maximum value of lift-to-drag ratio decreases to values 
ranging from 2.3 to 2.7 .

Examples of eleven and canard effectiveness as measured by the incremental pitching moment coefficient are shown in Fig. 12 to 15 . For subsonic/transonic speeds, the results are presented for $\alpha=0,5$ and $10 \mathrm{deg}$, and for supersonic speeds at $\alpha=0,10,20,30$ and 40 deg. It may be noted at Mach 0.3 and 0.6 , at alpha $=10 \mathrm{deg}$, the $10 \mathrm{deg}$ canard is less effective than a 5 deg canard because it is likely to have stalled.

The lateral/directional stability characteristics as expressed by the rolling and yawing moment coefficient derivatives $C_{l \beta}$ and $C_{n \beta}$ are shown in Figs. 16 and 17. For subsonic/transonic speeds, these derivatives, at a given angle of attack, were obtained by using the values of the rolling and yawing moment
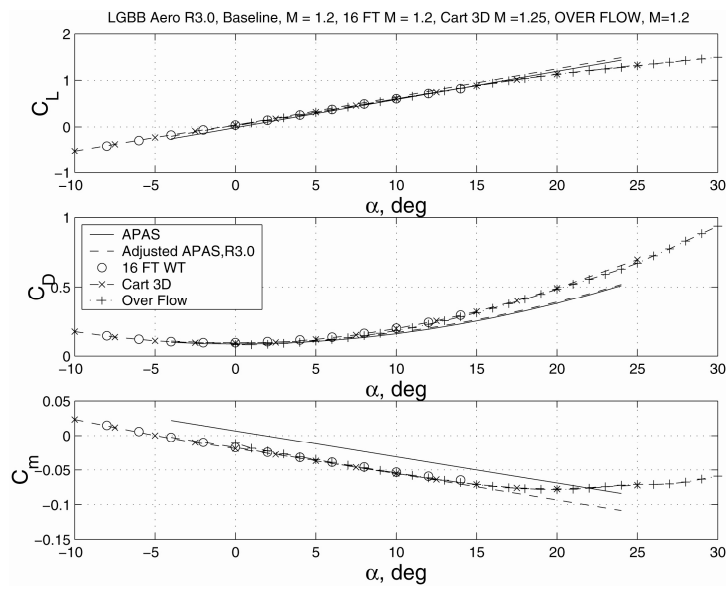

Figure 9. Comparison of longitudinal characteristics at Mach $=\mathbf{1 . 2}$. coefficients measured at $\beta= \pm 4 \mathrm{deg}$ and that for supersonic speeds at $\beta= \pm 2 \mathrm{deg}$. This approach of estimating the sideslip derivatives assumes that the coefficients vary linearly with sideslip with alpha held constant. Based the test data obtained at subsonic/transonic speeds with beta varying from -6 to +6 deg with alpha held constant at 0 and 12 deg this assumption was found to be generally true except for Mach numbers close to 1.0 where nonlinearities, particularly in yawing moment coefficient were observed.

An example of the nonlinearity in yawing moment coefficient at Mach 0.9 and 0.95 at $\alpha=12$ deg. is shown in Fig. 18. It is interesting note that the model is directionally unstable around $\beta=0$ but becomes stable at higher sideslip. A similar behavior was also noted for the X-34 model at transonic speeds ${ }^{4}$. Such local directional instability even if it were to occur on the full-scale vehicle when it flies through transonic speeds may not present any problems because it is bounded by stable condition. Since flow diagnostic tests were not performed, physical flow mechanism responsible for such nonlinear behavior is not clear. For supersonic speeds, the test data was obtained with sideslip varying from -6 to +6 deg with angle of attack held constant at 0,6,12,18,24 and $30 \mathrm{deg}$. The test data (not presented here) showed that the side force coefficient, rolling and yawing moment coefficients varied almost linearly with sideslip and the type of nonlinearity mentioned above was not observed.
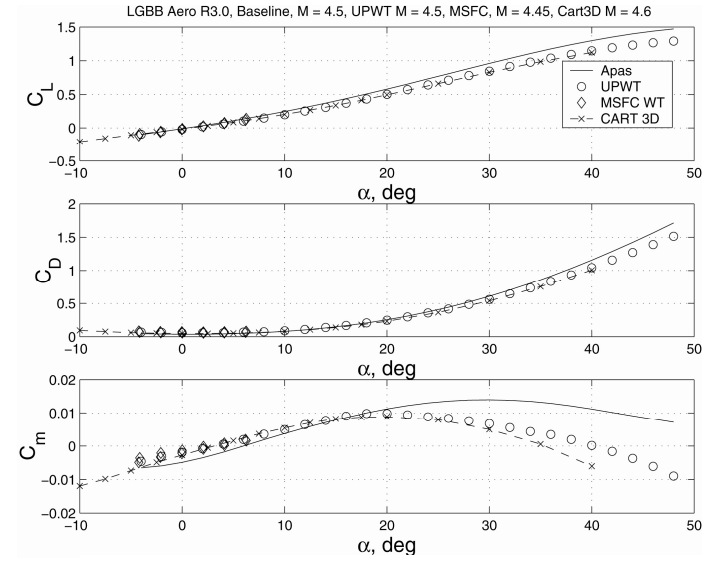

Figure 10. Comparison of longitudinal characteristics at Mach $=\mathbf{4 . 5}$.
The aileron effectiveness as measured by the incremental rolling moment coefficient at subsonic/transonic speeds $(\alpha=0,5 \mathrm{deg}$ and 10 deg) and supersonic speeds $(\alpha=0,10,20,30$ and $40 \mathrm{deg}$ ) are presented in Figs. 19 and 20. It may be observed that for a given angle of attack, in general, the effectiveness of ailerons as a roll control devices decreases at transonic speeds, recovers a little bit and decreases again at supersonic speeds.

The rudder effectiveness as measured by the incremental yawing moment coefficient for subsonic/transonic speeds is presented in Fig. 21 for $\alpha=0,5$ deg and $10 \mathrm{deg}$. It is observed that the rudder effectiveness decreases at high 
subsonic speeds but shows a modest recovery above Mach 1 . The incremental yawing moment coefficient due rudder deflection at Mach 1.6, 3.0 and 4.5 are presented in Figs. 22-24. It may be noted from these figures that the rudder effectiveness decreases with angle of attack because the rudder is shielded and is immersed in the low dynamic pressure wake of the wing and the fuselage. However, it exhibits a tendency to regain some of the effectiveness at high angles of attack around 30 deg which becomes noticeable at Mach 4.5 as shown in Fig. 24. Since flow diagnostic measurements were not done in this study, the flow mechanism that leads to this phenomenon is not clear.

\section{Glideback Performance:}

The initial conditions for the glideback trajectory corresponding to the staging point of the ascent trajectory were determined are as follows ${ }^{15}$ : altitude $=82,022 \mathrm{ft}$, velocity=2774.0 ft/sec, $\mathrm{M}=2.84$, dynamic pressure $=300.0 \mathrm{lb} / \mathrm{sft}$, flight path angle $=66.48 \mathrm{deg}$. At staging, the booster is flying in an upside down position.

In the optimized glideback trajectory (with cost function as the altitude margin) the booster returns to the launch site $356 \mathrm{sec}$ after separation at Mach 0.57 and an altitude of 46,070 ft. The profiles of flight path

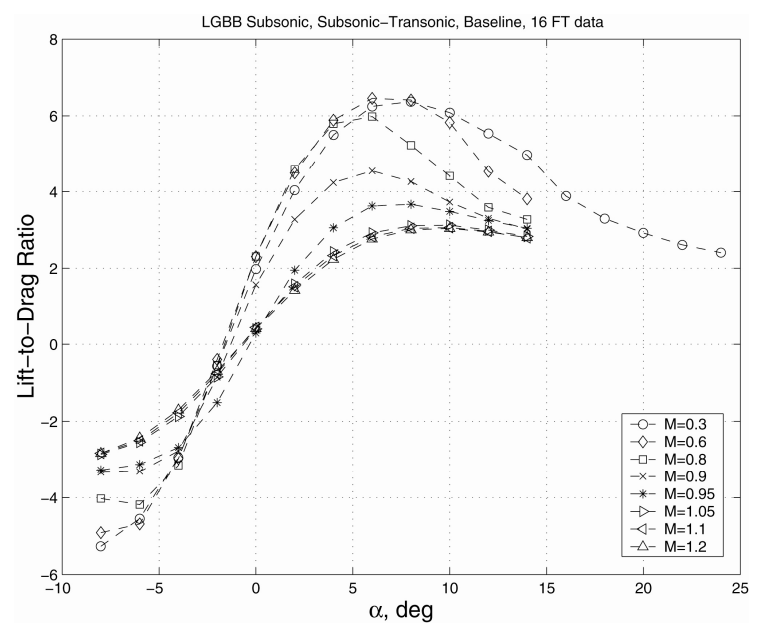

Figure 11(a). Lift-to-drag ratio at subsonic/transonic speeds.

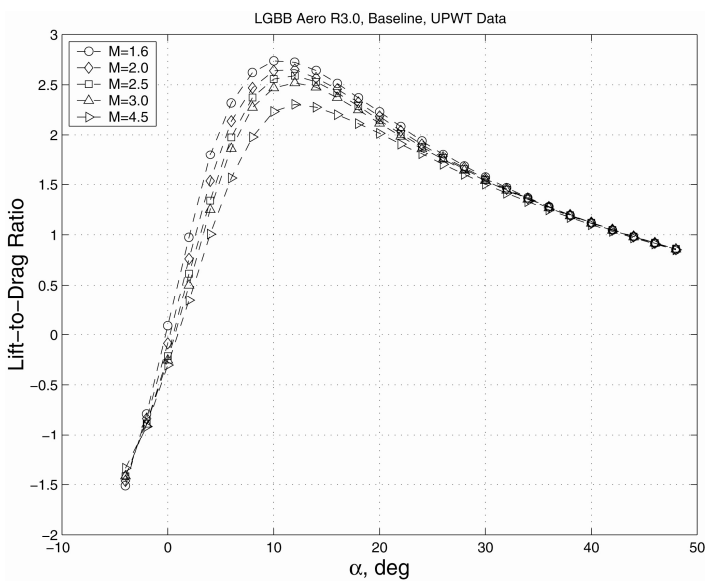

Figure 11(b). Lift-to-drag ratio at supersonic speeds. variables are shown in Fig. 25-28. After separation the booster continues to climb and its velocity decreases to $770 \mathrm{ft} / \mathrm{s}$ until apogee (maximum altitude) is reached at an altitude of $157,200 \mathrm{ft}$. After reaching the apogee, the altitude decreases and the velocity increases until it peaks at 1,735 ft/s when the dynamic pressure is large enough to cause the vehicle to decelerate. This change in dynamic pressure is illustrated in Fig. 27, which shows the initial decrease in dynamic pressure from the separation value of 300 psf to less than 10 psf between 25 and 108 sec. During this time the aerodynamic forces are small and hence have little effect on the trajectory. After 108 sec the dynamic pressure rises but never exceeds 200 psf. The normal acceleration constraint was enforced by adjusting the angle-of-attack profile. The initial 15 seconds of the profile was tailored to increase the angle-of-attack from 0 to $48 \mathrm{deg}$ (when booster is above Mach 1.6) without violating the $2.3 \mathrm{-g}$ limit on normal acceleration. The booster transitions to the highest possible

lpha value as soon as possible to maximize drag and arrest the booster's down range. As seen in Fig. 26, lpha is reduced to $20 \mathrm{deg}$ when the Mach number falls below 1.6 and is flown for $80 \mathrm{sec}$ at the top of the ballistic arc when dynamic pressure values are less than 10 psf. By 117 sec when dynamic pressure levels have risen and the Mach number has increased past 1.6, alpha is increased back up to 48 deg to further decelerate the vehicle. Once enough deceleration has occurred, alpha transitions to lower values where the lift-to-drag ratio is higher. At $146 \mathrm{sec}$ the vehicle rides the $2.3 \mathrm{~g}$ 
normal acceleration limit by modulating lpha for $31 \mathrm{sec}$ after which the optimal alpha profile is resumed to maximize the final altitude.

Also shown in Fig. 26 is the bank angle $(\sigma)$ profile. The initial bank angle is 180 deg because the booster was launched in a heads down orientation and remains in this orientation until staging point. At the start of the glideback, while the dynamic pressure is still substantial, the bank angle rapidly transitions to 80 deg to rotate the lift vector away from the full lift-down direction, thus affecting the flight path angle and the apogee altitude reached by the booster. The apogee altitude must be high enough to ensure a sufficient exchange between kinetic and potential energy. If the apogee altitude becomes too high, the down range will increase to the point where the drag losses may become excessive and affect the glideback performance. Once the apogee is passed, the booster is in a dive and the dynamic pressure begins to build up and the optimal bank profile for turning back to the launch site was flown. The elevon and canard deflection profiles are shown in Fig. 28. For the entire trajectory the elevon and canard deflections remained within their limits and their deflection rates remained below $10 \mathrm{deg} / \mathrm{s}$.

The ground track for the nominal glideback trajectory is shown in Fig. 29. Nearly the entire trajectory was flown over water. The booster travels a maximum distance of $20.3 \mathrm{~nm}$ from the launch site. The turn effectively begins near $100 \mathrm{sec}$ and is completed by $250 \mathrm{sec}$.
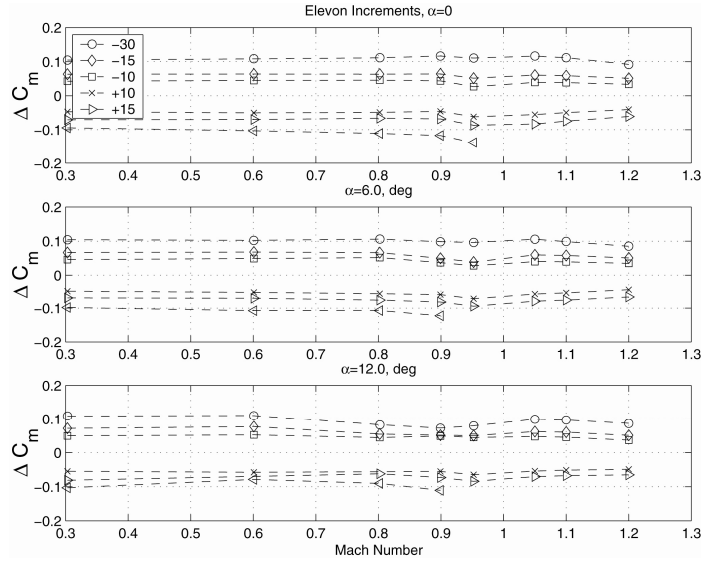

Figure 12. Elevon increments at subsonic/transonic speeds.
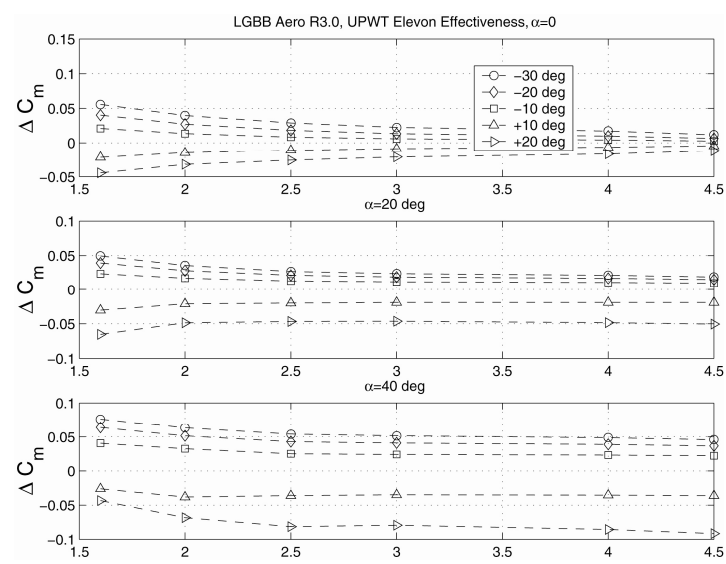

Figure 13. Elevon increments at supersomic speeds. 


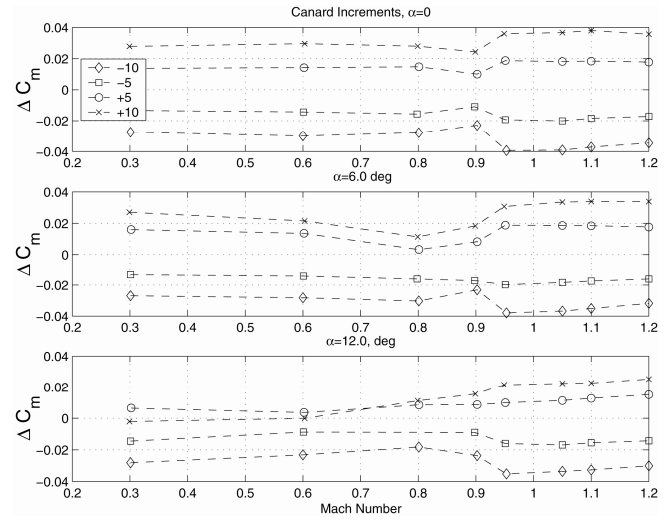

Figure 14. Canard inbcrements at subsonic/transonic speeds.
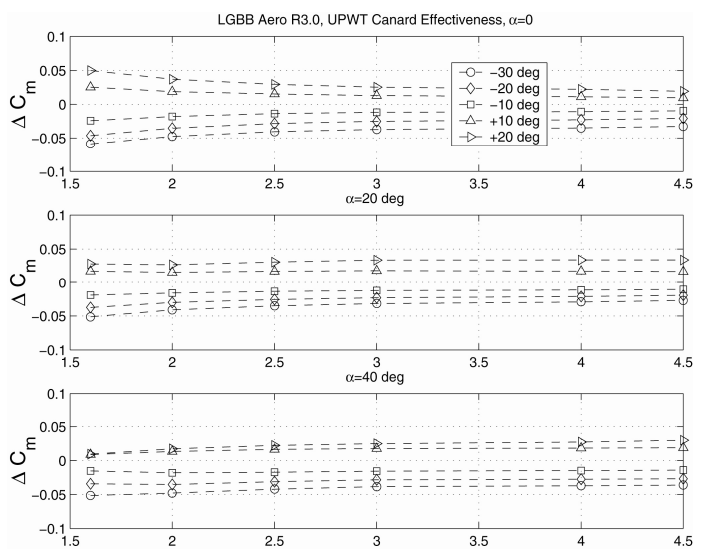

Figure 15. Canard inbcrements at supersonic speeds.
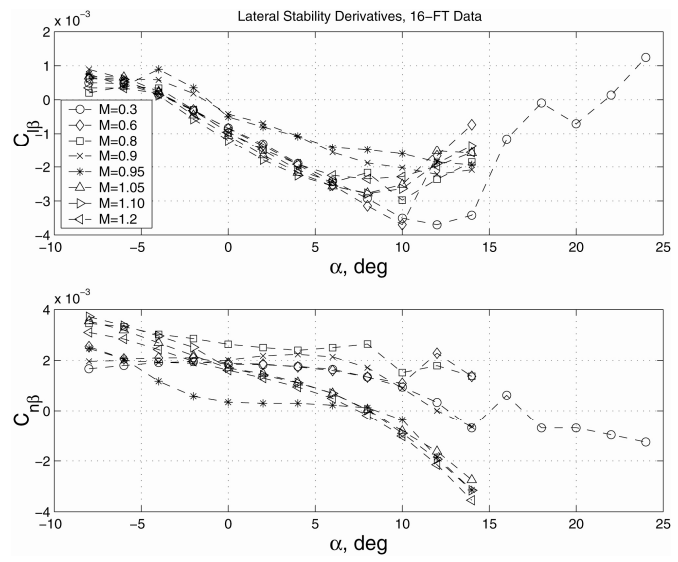

Figure 16. Lateral - directional stability characteristics at subsonic/transonic speeds.
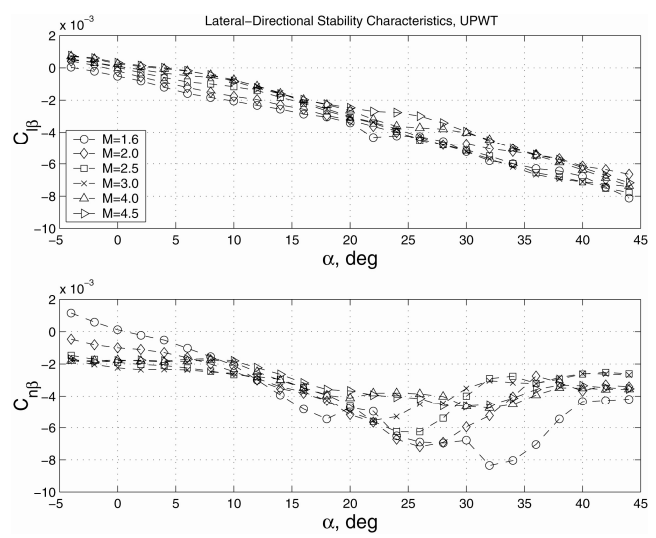

Figure 17. Laterial - directional stability characteristics at supersonic speeds.

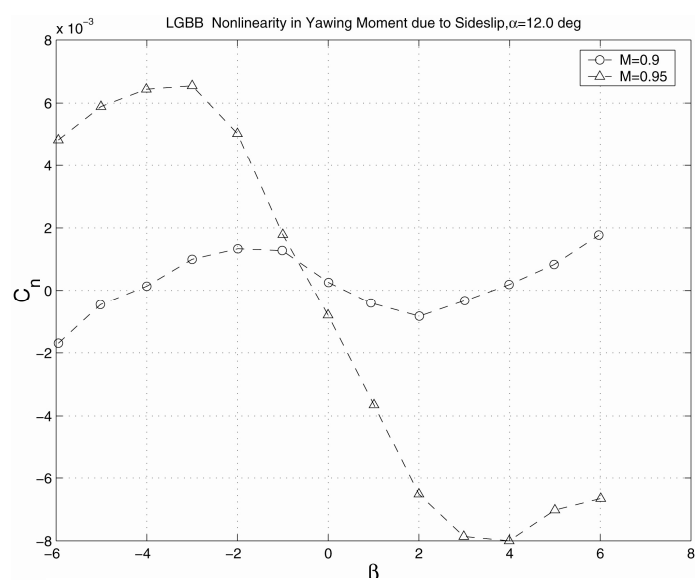

Figure 18. Examples of nonlinearity in the variation of yawing moment coefficient with sideslip at transonic speeds.

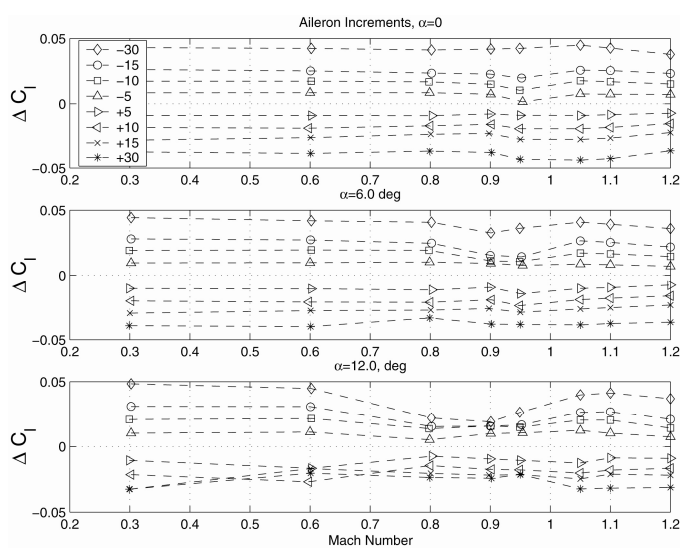

Figure 19. Aileron increments at subsonic/transonic speeds. 


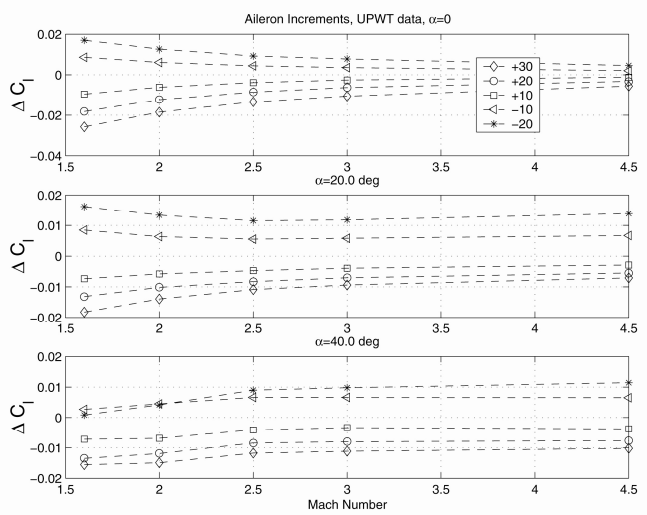

Figure 20. Aileron increments at supersonic speeds.

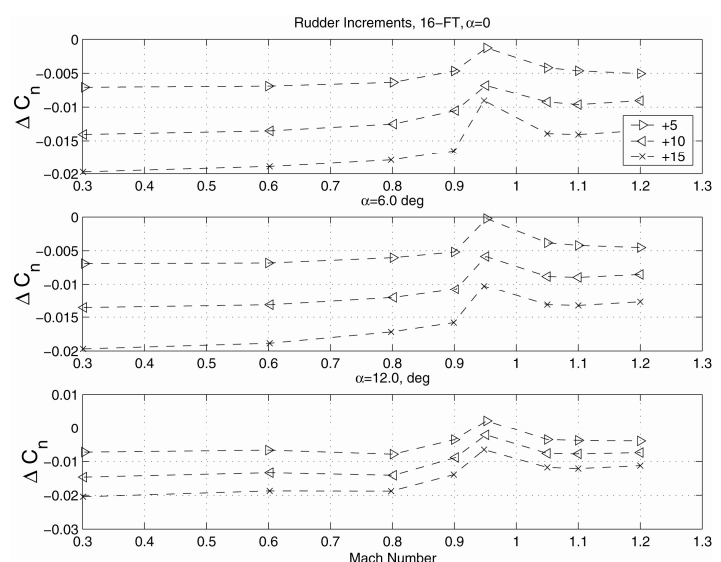

Figure 21. Rudder increments at subsonic/transonic speeds.

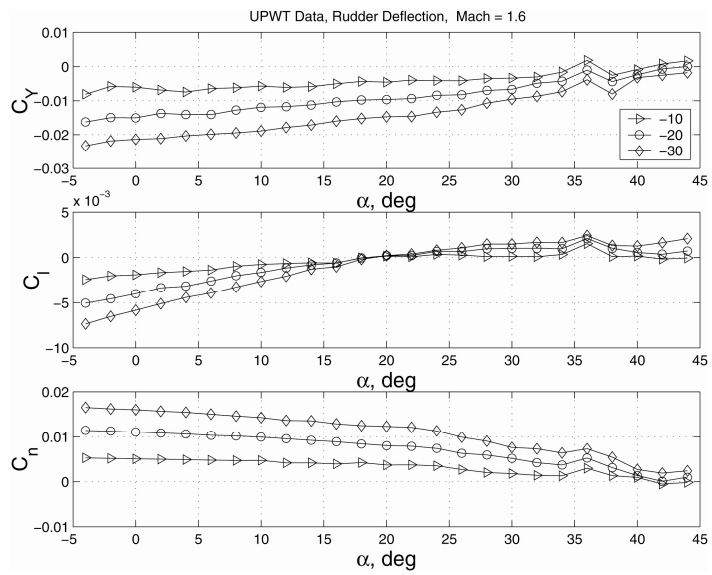

Figure 22. Rubber increments at $\mathrm{Mach}=1.6$.

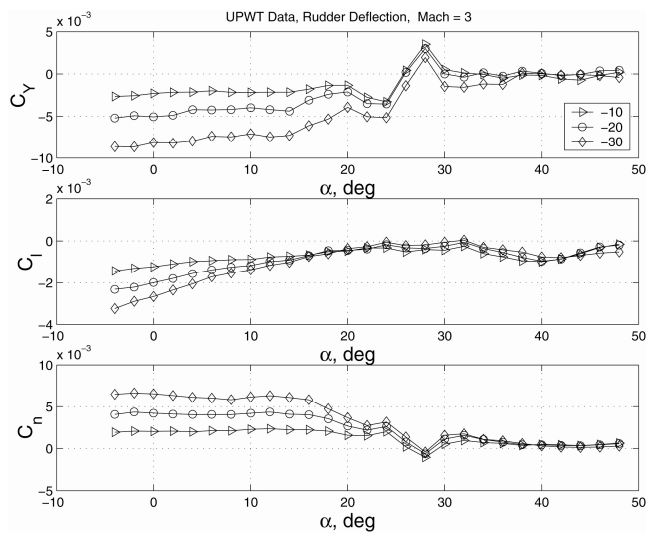

Figure 23. Rudder increments at $\mathrm{Mach}=\mathbf{3 . 0}$
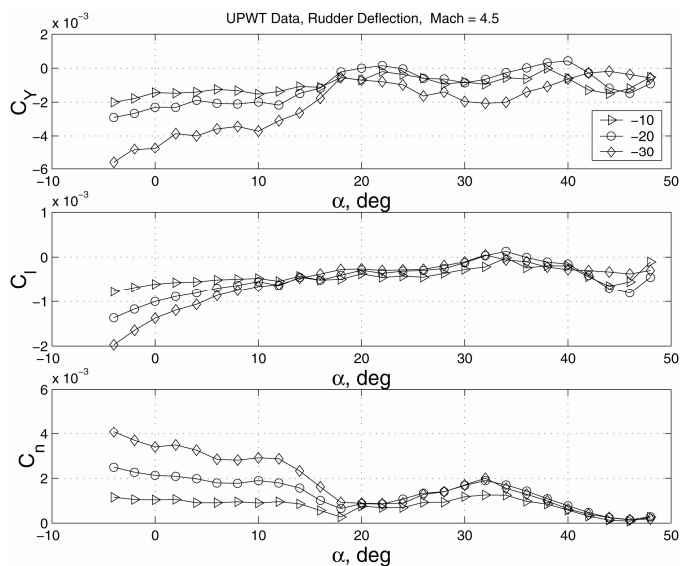

Figure 24. Rudder increments at Mach = 4.5

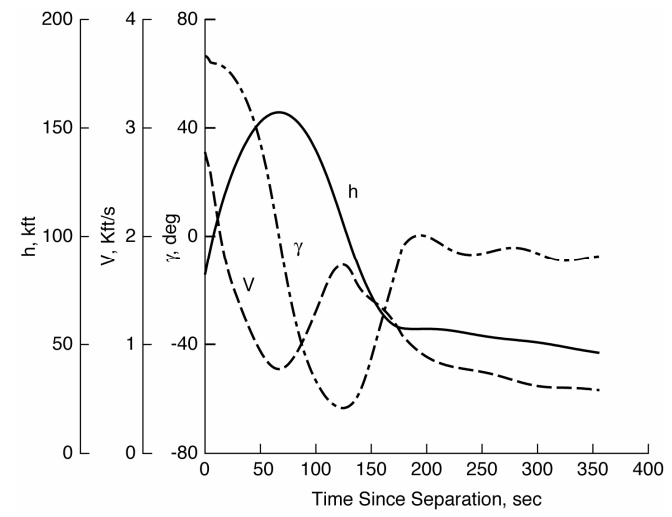

Figure 25. Altitude, velocity and flight path angle profiles for nominal glideback trajectory. 


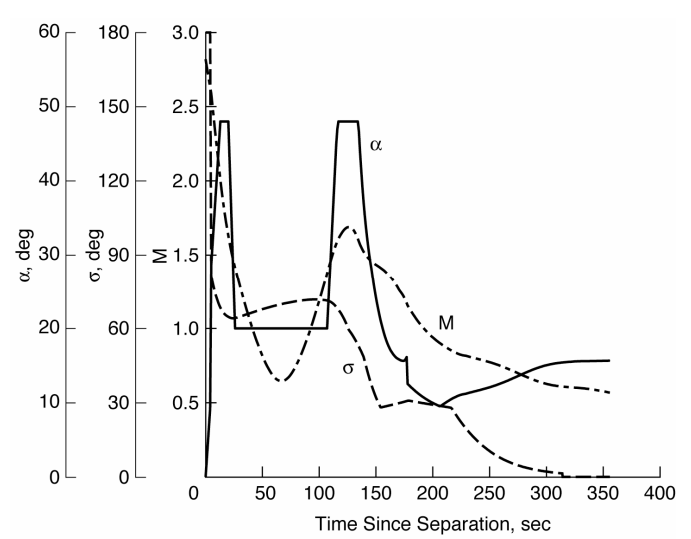

Figure 26. Angle of attack, bank angle and Mach number profiles for nominal glideback trajectory.

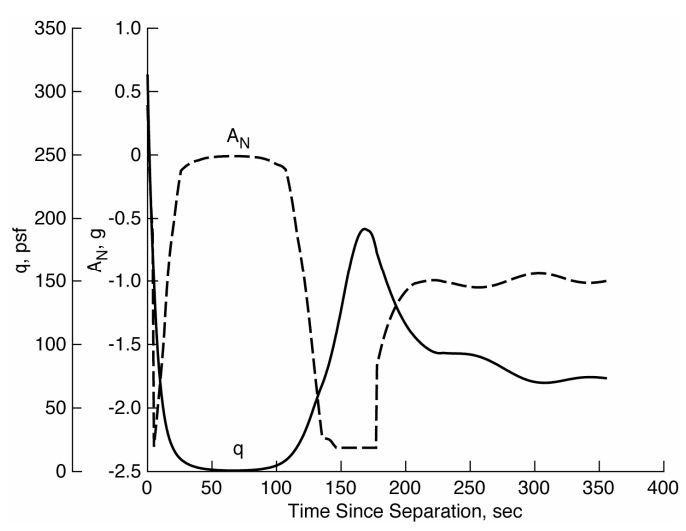

Figure 27. Variation of dynamic pressure and normal acceleration for glideback trajectory.

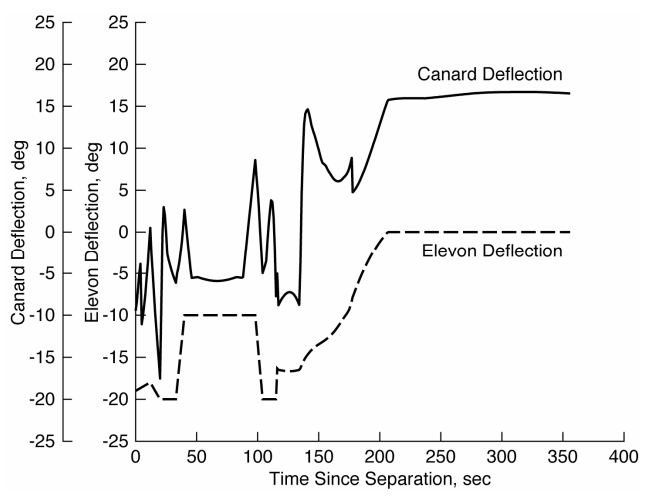

Figure 28. Canard and elevon deflections during glideback trajectory.

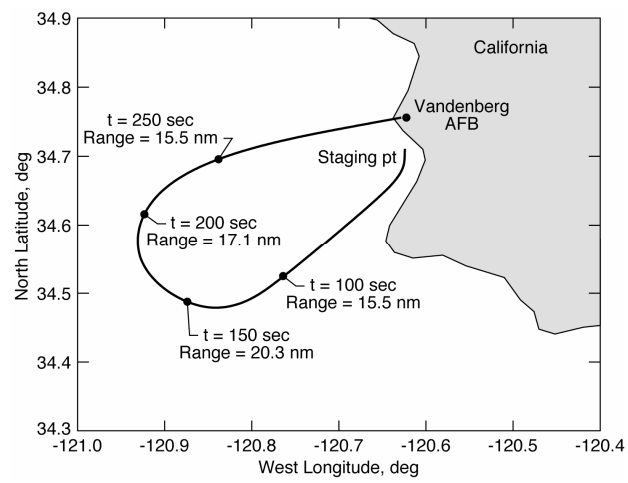

Figure 29. Ground track for glideback trajectory.

\section{Concluding Remarks}

The aerodynamic characteristics and glide back performance of the Langley Glide Back Booster (LGBB) are discussed in this paper. The LGBB is the reusable booster of an in-house small launch vehicle concept. An aerodynamic database was developed based on subsonic, transonic and supersonic wind tunnel test data generated at Langley. The engineering analysis code APAS was used to fill the gaps in the subsonic/transonic test data. The database covers high angles of attack up to $48 \mathrm{deg}$ at supersonic speeds and up to $20 \mathrm{deg}$ at subsonic/transonic speeds. The altitude margin when the booster returns to launch site was used as a performance metric for optimizing the three-degree-of-freedom glide back trajectory. It was found that the booster has around $46000 \mathrm{ft}$ altitude margin which may be adequate to handle winds, dispersions, off nominal conditions and the terminal area energy management. However, these issues were not addressed in this study. Also, the lateral/directional motion of the booster during the glide back to launch site was not considered. Further studies are necessary to address all these factors and demonstrate that the altitude margin attained in this study is quite adequate for the LGBB so that it can be considered as a viable concept of a reusable glideback booster for the small launch vehicle. 


\section{Acknowledgments}

Authors gratefully acknowledge Neil M. Chaderjian for OVERFLOW results, Michael J. Aftosmis and Reynaldo J. Gomez for CART 3D results, Wayne J. Borderlon and Alonzo L. Frost for MSFC wind tunnel test data, Robert M. Hall, Gary E. Erickson, Gregory J. Brauckmann for helpful discussions, Richard A. Wheless for graphics support.

\section{References}

1. Wertz, J.R., Biggs, M., and Conger, R.E., Status of Scorpius Low Cost Launch Services Program, Paper No. SSC97-X11-5, $11^{\text {th }}$ Annual AIAA/USU Conference on Small Satellites, 1997.

2. Aldrin, Buzz, Davis, H.P., The StarBooster $200^{\mathrm{TM}}$ System, A Cargo Aircraft for Space, AIAA/ASME/ SAE Joint Propulsion Specialists Conference, June 1999, Los Angeles, CA.

3. Aerodynamic Design Data Book, Vol. I, Orbiter Vehicle, Rockwell International Space Division, Rept. SD 72-SH-0060-1L, Downey, CA, Nov. 1977.

4. Pamadi, B.N. Brauckmann, G.J., Ruth, M.J., and Fuhrmann, H.D., Aerodynamic Characteristics, Database Development, and Flight Simulation of the X-34 Vehicle, Journal of Spacecraft and Rockets, Vol. 38, No. 3, pp 334-344.

5. Capone, F.J., Bangert, L.S., Asbury, S.C., Mills, C.T., and Bare, E.A.: The NASA Langley 16- Foot Transonic Tunnel, NASA TP-3521, Sept. 1995.

6. Jackson, C.M., Corlett, W.A., and Monta, W.J.: Description and Calibration of the Langley Unitary Plan Wind Tunnel, NASA TP-1905, Nov. 1981.

7. Borderlon, W. J., Frost, A.L., and Reed, D, K.: Stage Separation Wind Tunnel Tests of a Generic TwoStage-to-Orbit Launch Vehicle, AIAA Paper 2003-4227, July 2003.

8. Braslow, Albert 1.; Hicks, Raymond M.; and Harris, Roy V., Jr.: Use of Grit-Type Boundary-LayerTransition Trips on Wind-Tunnel Models. NASA TN D-3579, 1966.

9. Stallings, Robert L., Jr.; and Lamb, Milton: Effects of Roughness size on the Position of BoundaryLayer-Transition and on the Aerodynamic Characteristics of a 55-degree Swept Delta Wing at Supersonic Speeds. NASA TP-1027, 1977.

10. Wassum, Donald L.; and Hyman, Curtis E., Jr.: Procedures and Requirements for Testing in the Langley Research Center Unitary Plan Wind Tunnel. MASA TM-100529, 1988.

11. Bonner, E., Clever, W., and Dunn, K.: Aerodynamic Preliminary Analysis System II, Part I- Theory, NASA CR-182076, April 1991.

12. Sova, G. and Divan P.: Aerodynamic Preliminary Analysis System II, Part II- User's Manual, NASA CR-182077, April 1991.

13. Brauer, G.I., Cornick, D.E., and Stevenson, R., Capabilities and Application of the Program to Optimize Simulated Trajectories, NASA CR-2770, February 1977.

14. Justus, C.G. and Johnson, D.L., "The NASA/ MSFC Global Reference Atmospheric Model - 1999 Version (GRAM-99),” NASA TM-1999-209630, May 1999. 
15. Pamadi, B.N., Tartabini, P.V., and Starr, B.R., Ascent, Stage Separation and Glideback Performance of a Partially Reusable Small Launch Vehicle, AIAA Paper 2004-0876.

16. Aftosmis M.J., Berger M.J., and Melton J.E., "Robust and Efficient Cartesian Mesh Generation for Component-Based Geometry”, AIAA Paper 97-0196, Jan. 1997.

17. Jespersen D.C., Pulliam T.H., and Buning P.G., "Recent Enhancements to OVERFLOW", AIAA Paper 97-0644, Jan. 1997. 